\title{
OLIVERIO GIRONDO EN EL PAISAJE CULTURAL DE LOS MONTES DEL TORDILLO. Estudio de las analogías existentes entre el paisaje en la poesía de Girondo y de su poesía en la fisiografía del lugar.
}

\author{
Casali Urrutia, Marina A.; Meo Laos, Verónica G, \\ Fundación Ortega y Gasset de Argentina \\ Directora de la investigación: Marta Campomar e- \\ gestionculturalfoga@ortegaygasset.com.ar
}

\section{RESUMEN}

El siguiente trabajo tiene por objeto indagar en las analogías existentes entre el paisaje de los Montes del Tordillo y la obra poética de Oliverio Girondo. Nuestro abordaje se realiza desde dos perspectivas en simultáneo: las huellas del paisaje en sus poemas y, de manera análoga, las huellas de aquéllos en la fisiografía de los montes.

La hipótesis de partida es que, aun cuando no lo puntualice en ninguno de sus poemas, el poeta argentino conoció en profundidad el paisaje de los Montes del Tordillo de modo que su vínculo con él se asocia a lo que, la geografía humanista denomina topofilia, es decir, el sentimiento de apego, de apropiación del espacio que liga a las personas a los lugares con los que se sienten identificados. Yi Fu Tuan considera que el paisaje trasciende lo personal para devenir en símbolos y, en este sentido, postulamos que es posible rastrear esos lazos en la obra de Oliverio Girondo. Al tiempo que es posible observarlos en el paisaje de los montes del Tordillo.

Este trabajo de indagación bibliográfica se inscribe en un proyecto de investigación cualitativa de mayor envergadura que, desde la perspectiva fenomenológica y a través del método etnográfico y de entrevistas en profundidad así como caminatas perceptuales y vivenciales, indaga en las percepciones, subjetividades y horizontes de representaciones de los habitantes y de qué manera éstos coexisten con las huellas de los que lo habitaron y transitaron por el lugar en el pasado conformando un palimpsesto de resonancias de historias y relatos que configuran el paisaje cultural de los Montes del Tordillo.

Palabras clave: paisaje cultural, toponimia, huellas, Oliverio Girondo.

\begin{abstract}
The following work aims to investigate the analogies between the landscape of the Montes del Tordillo and the poetic work of Oliverio Girondo. Our approach is carried out from the perspectives simultaneously: the traces of the landscape in his poems and, analogously, the traces of the bodies in the physiography of the montes. The starting hypothesis is that, even though he does not specify it in any of his poems, the Argentine poet knew in depth the landscape of the Montes del Tordillo so that his link with it is associated with what human geography calls topophilia, that is, the feeling of attachment, of appropriation of space that links people to the places with which they feel identified. Yi Fu Tuan considers that the landscape transcends the personal to become symbols and, in this sense, we postulate that it is possible to trace those links in the work of Oliverio Girondo. While it is possible to observe them in the landscape of the montes of Tordillo.

This work of bibliographic research is part of a larger qualitative research project that, from the phenomenological perspective and through the ethnographic method and in-depth interviews as well as perceptual and experiential walks, investigates the perceptions, subjectivities and horizons of representations of the inhabitants and how they coexist with the traces of those who inhabited it and passed through the place in the past, forming a palimpsest of resonances of stories and stories that make up the cultural landscape of the Montes del Tordillo.
\end{abstract}

Keywords: cultural landscape, place names, topophilia, footprints 


\section{i. INTRODUCCIÓN}

De acuerdo con el trabajo de Alejandra Mascioli, el proceso colonizador al Sur del rio Salado en la provincia de Buenos Aires se habría iniciado entre fines del siglo XVIII y las primeras décadas del siglo XIX cuando algunos colonos deciden afincarse en la zona e instalar sus establecimientos productivos.

Entre 1816 y 1819, durante la gestión de Juan Martín de Pueyrredón como Director Supremo de las Provincias Unidas del Río de La Plata, se realiza un avance hacia el sur y el oeste del territorio de lo que, con posterioridad, se denominó provincia de Buenos Aires. Por aquel entonces los márgenes del rio Salado oficiaban de límite instituido entre las sociedades de colonos blancos y los pueblos nativos.

En este proceso de avanzada contra el salvaje -como suele denominarlo la historiografía dolorense- se concreta la fundación del primer pueblo ubicado al Sur del río Salado. En 1817, en un ejido de tres cuartas leguas de frente por dos de fondo, situado entre las tierras de Julian Martinez de Carmona y Miguel Gonzalez Salomón en las inmediaciones de los Montes del Tordillo, se crea el curato de Nuestra Señora de los Dolores, bajo la autoridad del Presbítero Francisco de Paula Robles y la Comandancia Militar y Política de las Islas del Tordillo a cargo de Pedro Antonio Paz. Un año después se funda el pueblo de Dolores.

El nombre alude al apócope derivado de la advocación de la Virgen como Nuestra Señora de los Siete Dolores o "la Dolorosa" y es, hasta el establecimiento de los límites actuales del partido en 1865, objeto de cambios respecto a la extensión de su territorio y a la jurisdicción de sus autoridades. En un primer momento se encuentra bajo la jurisdicción de los Alcaldes de Hermandad y Tenientes del Fuerte de Nuestra Señora de la Merced de Chascomús. Posteriormente es adscripto al partido de Monsalvo tras su creación entre 1821 y 1825. Recién, a partir de 1831, comienza a existir como partido de Dolores con el establecimiento de un Juzgado de Paz propio. En 1856 se establece el estado municipal.

Antes de que se constituyera como partido, el pueblo de Dolores es vuelto a fundar en 1826 por iniciativa de Ramón Lara en compañía del religioso Ramón González como consecuencia de la destrucción perpetrada en dos oportunidades, 1821 y 1823, por la incursión de malones indígenas que habían sido masacrados y despojados de sus tierras en los campos de Francisco Hermógenes Ramos Mejía. En 1839, tras el levantamiento conocido como Revolución de los Libres del Sur, en el que participan de manera activa pobladores de Chascomús y Dolores, el gobernador de la provincia de Buenos Aires, Juan Manuel de Rosas, decide dividir a este último partido en otros tres: Dolores, Pila y Tordillo. De acuerdo a lo expuesto en el decreto del 25 de diciembre de 1839, antes de esa fecha el partido de Dolores abarcaba una amplia superficie hoy comprendida por Dolores, Castelli, Tordillo, parte de Pila, parte de General Guido y parte de General Lavalle.

i. 1. Los Montes del Tordillo: breve historia

El o los Montes del Tordillo pertenecen al partido de Dolores de hecho, como hemos visto, fue designado lugar, aconteció antes que el propio partido. Su topografía particular se distingue de la planicie general de la región. Se trata de un paisaje cubierto de lomadas pobladas de árboles que conviven con depresiones que preservan la humedad en las tierras. Las especies nativas predominantes son los talas (celtis tala) y los coronillos (scutia buxifolia).

Varias crónicas de viajeros se refieren a los montes del Tordillo y su paisaje particular, entre ellos William "Guillermo" Miller, militar inglés de infantería de marina (Winghan, 1795-Lima 1861) que participó en las campañas navales de la guerra de la Independencia junto al almirante Manuel Blanco Encalada describe:

El Monte del Tordillo tiene ocho leguas de ancho y se extiende desde la costa del mar hasta la Patagonia en dirección SO y se halla infestado de tigres que más propiamente pudieron llamarse leopardos, también hay algunos leones, muy parecidos a los de África en su figura, tamaño y complexión. El color de su piel es tostado con manchas blanquinosas, la cabeza grande y redonda, los ojos centellantes y la nariz chata (Miller, J. 1997).

La descripción de la fauna autóctona del lugar coincide con la de otros cronistas viajeros que pasaron por allí como la del jesuita Thomas Falkner, Juan de Garay, el virrey Vértiz, J. De la Villa, agrimensor que mensuró un campo de Manuel Rico (primer intendente de Dolores) en 1826 . Oliverio Girondo hablará en Campo Nuestro (1946) en los mismos términos sin citar el lugar de manera específica, como veremos más adelante. Juan Carlos Pirali, dolorense recopilador de historia local, puntualiza que la madera de las especies arbóreas nativas fue una materia clave para la construcción de viviendas y cercos pero, que a la vez, también generó una importante actividad del sector primario vinculada a la explotación forestal. De este modo, la fabricación 
de carbón, fue el principal motor de la economía de la zona. Francisco Ramírez fue el propietario de la tropa de carretas en las que se transportaba el material hasta Buenos Aires y el empresario que monopolizó el comercio carbonero. El dinamismo de la economía local atrajo a una importante mano de obra, principalmente masculina, que se trasladó con sus familias. El agreste paisaje de los montes fue transformándose poco a poco en un lugar habitado por personas de biografías diversas atraídas por la oportunidad de trabajo. Así hombres y mujeres compartían el espacio con veteranos de las guerras por la independencia, con desertores y "vagos" como los definió el capitán Ramón Lara en una carta al gobierno en 1816, cuando desde Kakel Huincul, llegó hasta la carbonería de Ramírez y "aprehendió a siete desertores y vagos que había allí" (Pirali, J. C.: 2010). Posiblemente cautivados por las oportunidades laborales y de dinero al amparo de una geografía agreste y de difícil acceso, también fue creciendo la prostitución y el juego. Francisco de Paula Robles, a cargo del curato de de Nuestra Señora de los Dolores, escribe atribulado a Juan Martín de Pueyrredón explicándole el dilema moral ante el cual su misión eclesiástica tambaleaba sin un norte fijo: "Siendo este partido la madriguera de mujeres casadas en otra parte y que aquí lo pasan por tal con otros, y la de solteras abrigadas por los mismos jueces, persuádase V. E. la triste situación en que me encontré y me encuentro hasta el presente" (Pirali, J. C.: 2010).

Los Montes del Tordillo permanecieron en poder de la provincia de Buenos Aires hasta 1865, cuando le fue entregada a la municipalidad de Dolores la explotación exclusiva de la economía forestal. A raíz del desmonte desmedido y la falta de control, desde el estado municipal deciden realizar las mensuras del lugar en 1872, a cargo del agrimensor Antonio Lagos. En 1880 se autoriza por ley provincial 1.183 a lotear y vender el terrero en subasta pública, excepto el sector ocupado por la laguna del Tordillo. En total, el área vendida comprendía 25 mil hectáreas divididas en 36 lotes. Los principales compradores fueron Ignacio García Cuerva (21 lotes), Juan Girondo y su cuñado Francisco Uriburu (3 lotes), Celindo Castro (4 lotes), Alejandro Bustos (3 lotes), Julio Ferrari (2 lotes) y Rufino Córdoba (1 lote).

El 24 de diciembre de 1937 y mediante la ley $4.621^{1}$, la legislatura bonaerense autoriza al Poder Ejecutivo para declarar de utilidad pública las fracciones de tierra ocupadas por los Montes del Tordillo, pobladas por montes naturales y para que adoptase las medidas pertinentes para que en esas "reservas naturales" se instalara un parque provincial con el propósito de evitar la tala indiscriminada.

Con el tiempo y el avance de la frontera agropecuaria, el paisaje de los montes fue abriéndole espacios a la planicie para alimentar al ganado lanar, primero, y vacuno para después, con el correr de los días, en lugar de la abigarrada presencia boscosa de talas y coronillos hogar de los pobladores fugitivos de sus propios pasados, las carbonerías humeantes y los asentamientos precarios de inmigrantes provenientes del Oriente Medio las lomadas e islas del Tordillo fueran cercadas por alambrados en cuadrículas que limitaron la propiedad de la tierra.

\section{Desarrollo}

\section{1. Marco teórico y metodología de la investigación.}

De acuerdo con la definición del Convenio Europeo del Paisaje, el paisaje es un área -tal y como lo percibe la población- cuyo carácter es el resultado de la interacción dinámica de factores naturales y humanos. Por lo tanto, se concibe a la vez como una realidad física y como la representación que culturalmente nos hacemos de ella. Es la fisonomía geográfica de un territorio con todos sus elementos naturales y antrópicos y también los sentimientos y emociones que despiertan en el momento de contemplarlos.

Los estudios del paisaje inaugurados por Carl Sauer (La morfología del paisaje, 1925) ponen énfasis en el enfoque holístico que busca hallar el sentido de lo observado en la forma en que se integran los elementos geológicos, edafológicos, geomorfológicos, de flora y fauna con los económicos, demográficos, culturales y políticos. Para ello se requiere un trabajo de campo consistente en la observación directa, complementada con la investigación documental. Con posterioridad, la categoría del paisaje fue abordada desde dos dimensiones: La primera, denominada el flaneur, que se basa en la posibilidad de integrar elementos del paisaje como una forma de acercamiento inicial al conocimiento y a la percepción de las condiciones con las que un lugar se identifica, lo que permite, a su vez, reconocer los procesos particulares desarrollados en esos lugares. Esta visión ha sido usada por arquitectos y diseñadores del paisaje para transformar los entornos y mejorar las condiciones de desarrollo.

El Poder Ejecutivo sanciona y promulga, en 1937, la ley 4.621 que declaraba de utilidad pública las fracciones de tierras ocupadas con montes naturales existentes en los partidos de Magdalena, Castelli, Dolores, General Conesa y General Madariaga para reservas naturales o instalación de parques provinciales. 
La segunda dimensión tiene un referente más analítico que intenta rescatar un concepto tradicional de la geografía que reconoce procesos que difícilmente pueden ser identificados, por lo que se requiere apelar a la dimensión cultural-simbólica para la identificación de tales procesos. Joan Nogué, junto con otros autores, define el paisaje como "un producto social, como resultado de una transformación colectiva de la naturaleza y como la proyección cultural de una sociedad en un espacio determinado". Estos cambios son resultado de la transformación de los paisajes originales, modificados por la sociedad, que los convierten de naturales en culturales, y en centros de significación y de símbolos que expresan pensamientos, ideas y emociones de tipos muy diversos.

Hoy día, se concibe al paisaje a partir de las miradas, como una manera de ver e interpretar; miradas que son construidas y responden a una ideología que busca transmitir una determinada forma de apropiación del espacio. Bajo esta concepción, existen formas de paisaje múltiples, simultáneas, diferentes y, algunas veces, hasta en competencia.

Desde otro enfoque, el paisaje es entendido como una creación cultural del ser humano y se vincula a la noción de texto, entendido éste en tanto unidad comunicativa formada por un enunciado o un conjunto de enunciados que transmite un mensaje con sentido completo. El texto excede a los enunciados escritos y puede ser representado a través de pinturas, mapas, formas urbanas e incluso instituciones sociales. Todos ellos pueden ser entendidos en términos de prácticas de significación que se van construyendo al tiempo se van leyendo. A partir de ello se identifican narraciones, discursos y metáforas que serán leídas por comunidades textuales; es decir, grupos de personas que tienen bases de entendimiento semejantes para la interpretación. El análisis del paisaje cultural como sistema significante se apoya en la teoría estructuralista de base saussureana.

Siguiendo esta perspectiva todo paisaje es un texto cargado de mensajes que le confieren un sentido. Quienes lo modelan, intentan plasmar en la realidad sus perspectivas, sus sueños y esperanzas (Claval, P.: 2002). También intentan justificar su dominio a través de las huellas fijas en el suelo y de las palabras a través de las cuales nombran y transforman así los lugares en territorios. Los territorios con discurso equivalen a paisajes con imaginario con una identidad paisajística propia que les confiere un sentido de pertenencia de lugar. El mundo mismo es un dato de la percepción que está estructurado por discursos. Por eso, para desentrañar el sentido, es necesario realizar un análisis minucioso de los testimonios y experiencias de aquellos que viven y sienten el paisaje, de la trama de actores que construyen y reconstruyen la idiosincrasia territorial local.

Desde nuestra perspectiva el paisaje es el resultado de la transformación colectiva de la naturaleza o sea la proyección cultural de una sociedad en un momento determinado, de allí su carácter dinámico. A través de sus culturas, las sociedades humanas transforman los paisajes naturales en paisajes culturales, caracterizados no solo por una determinada materialidad sino por la transposición de los valores personales y sentimientos al paisaje. Por ende se trata de algo dinámico, en continua mutación, en producción y reproducción intersubjetiva de sentidos. Dicho de otro modo, el paisaje tiene y ha tenido un rol clave en la conformación de identidades culturales porque él mismo es cultura.

Coincidimos con el concepto de idiosincrasia territorial local aportado por Joan Nogué (Nogué, J.: 2010). En general, la gente se siente parte de un paisaje con el que establece múltiples y profundas complicidades aun cuando hayan sufrido el impacto de las telecomunicaciones, la estandarización de las modas, la mundialización de los mercados o la mayor velocidad de los sistemas de transporte. En este sentido el paisaje constituye el sustrato sobre el cual se construyen las identidades imaginadas de las que nos habla Benedict Anderson, las cuales -independientemente de la desigualdad y la explotación que pueda prevalecer en cada caso- se concibe siempre como un compañerismo profundo, horizontal (Anderson, B.:1993).

Pero, asimismo, las sociedades nacen de la fusión, del enredo y la imbricación de lo que Anthony Giddens denomina locales es decir, de grupos más o menos localizados que forman la unidad de base de la vida social y de la realidad cultural. Aquellas personas que viven y han vivido en los mismos lugares y participaron de similares mundos de la vida, se comunican, entablan relaciones intersubjetivas de construcción del sentido. De allí que identidad y sentido coincidan en tanto procesos de subjetivación de las significaciones que atribuimos a las cosas del mundo.

En consonancia con ello la geografía humanista de Yi Fu Tuan sostiene que el lugar está definido por la perspectiva empírica que las personas tienen del espacio, es decir por las experiencias de quienes lo ocupan que hacen que ese lugar sea significativo para ellos. Introduce el concepto de topofilia al que define como el 
sentimiento de apego que liga a los seres humanos a aquellos lugares con los que, por una u otra razón, se sienten identificados y generan un significativo apego o pertenencia al mundo.

Asimismo la experiencia o conocimiento del espacio no solo involucra el sentido de la vista que provee la percepción tridimensional y es el que tiene preeminencia en términos de percepción del espacio sino que también participan el gusto, el olfato, el oído y la sensibilidad de la piel que, si bien no permiten una experiencia espacial directa, en combinación con la vista y el tacto enriquecen la aprehensión del carácter espacial y geométrico del mundo. Así lo óptico y lo háptico o táctil cooperan en la percepción de los espacios vividos. En otras palabras, el paisaje es producto tanto de la percepción de los sentidos como del sentimiento intelectual y pasional.

En tanto construcción social y cultural, el paisaje de los Montes del Tordillo puede ser estudiado desde la dimensión textual, en tanto trama de enunciados que se imbrican para dar cuenta de una unidad discursiva de sentidos en el seno de la reproducción social. Asimismo, la poesía de Oliverio Girondo, uno de los tantos personajes viajeros que fueron cronistas del paisaje de los montes, en tanto corpus, también puede ser abordado desde el análisis textual comparativo con vistas a desentrañar la trama de relaciones de sentidos que vinculan la obra poética con el terruño o el sentimiento de apego hacia el lugar a la luz de la categoría de topofilia. En este sentido, dentro de la obra girondiana impregnada de su propia experiencia de movilidad, es posible observar que el campo es una una referencia constante. De todos modos, es en su libro Campo Nuestro (1946) donde el paisaje pampeano es el tópico vertebrador que da sentido al poema largo que da nombre al libro.

En virtud de ello, a los fines de recabar evidencia empírica, se realizó en primer término una indagación bibliográfica en la Obra Completa del poeta argentino para indagar en la presencia o ausencia de las huellas del paisaje de los montes en aquélla. También, dado que se trata de una investigación fenomenológica, se realizaron caminatas perceptuales y vivenciales por los Montes del Tordillo para recabar datos en el campo y también se recurrió al método cartográfico a fin de analizar la fisonomía del paisaje desde diversas escalas. En resumen, dado que nuestra hipótesis de partida es la topofilia respecto del paisaje de los montes que subyace a la poesía de Oliverio Girondo, el siguiente trabajo de investigación pone énfasis en indagar de qué manera paisaje y poesía se vinculan, articulan entre sí y se espejan estableciendo un diálogo de sentidos que pueden ser desentrañados si entendemos que, tanto uno como el otro, son unidades textuales atravesadas por numerosos enunciados imbricados de manera simultánea.

\section{II. b. El paisaje de los Montes del Tordillo y la poesía de Oliverio Girondo: una urdimbre de huellas entretejidas.}

Recordemos que espacios vividos pueden ser vistos como paisajes con imaginario cargados de una identidad paisajística propia que les confiere un sentido de pertenencia. A la luz de este presupuesto, el significante Montes del Tordillo adquiere densidad a partir de un relato mítico que da origen al sentido de lugar y es la historia que alude a un caballo salvaje de pelaje tordillo o grisáceo cuya bravura y espíritu indomable lo llevó a inmolarse en las aguas de la laguna homónima antes de caer bajo el yugo de la montura. Sin embargo, por un curioso deslizamiento semántico, el relato originario se confunde en la toponimia con los Montes de Girondo debido a la extensión de los campos que, en el pasado, pertenecieron a Juan Girondo y su cuñado, Francisco Uriburu. Aun hoy día es posible hallar ese topónimo en las identificaciones catastrales y sitios de Internet ${ }^{2}$ que hacen referencia a la estancia Girondo ubicada en Dolores, Buenos Aires, en las siguientes coordenadas: Latitud: -36.3833 Longitud: $-57.5167^{3}$. El patronímico familiar sobrevivió a la presencia elusiva del poeta en los montes pero, a la vez, cooperó en construir la trama de sentidos que configuró la identidad paisajística del lugar.

Siendo la estancia Girondo una heredad familiar es posible conjeturar que el poeta Oliverio conoció en profundidad la zona no solo a través de la experiencia vivida desde la infancia sino también a través de los relatos que pudieron haber circulado en su entorno íntimo.

El vínculo entre el terruño y las personas se produce a partir de la observación y la percepción a través de los sentidos. Es importante señalar que esa percepción no está ceñida a una mirada experta sino que es propia de lo humano; lo que cambia es la particularidad en la esencia de cada uno que, en su expresión,

2 Cfr.: https://www.yr.no/place/Argentina/Buenos_Aires/Estancia_Girondo/

$3 \mathrm{http}: / / \mathrm{www}$.dices.net/mapas/argentina/mapa.php?nombre=Estancia-Girondo\&id=40414 tienen mis propias venas. Cualquier dolor lastima mi carne, mi esqueleto. Las veces que me he muerto al ver matar un toro! (...) 
conforma las partes de un todo. Ninguna mirada es más valiosa que la otra sino que todas construyen la trama de la realidad que cobra sentido a partir de la construcción colectiva de los actores intervinientes. Cada uno de ellos, desde lo delicado de su sensibilidad, otorga sentidos. Para Oliverio Girondo fue la palabra poética, para Thomas Falkner o William Miller: la crónica de viajes, para los vecinos: las anécdotas cotidianas o el relato del tordillo indómito vinculado al mito del héroe que da origen a los montes y les confiere sentido.

De qué manera se imprimen las huellas de ese paisaje pampeano de lomadas e islas en la poesía girondiana. Desde nuestra perspectiva, coincidimos con que en gran parte de su obra se percibe el gozo de experimentar la certeza de que estamos constituidos por un conjunto de relaciones constitutivas, relaciones de movimiento y de reposo entre partículas lo que conduce a la evaporación del yo (Jarkowski, A.: 2001). En otras palabras es la conciencia del yo que se despliega hasta consustanciarse con las cosas, con los otros, con el paisaje mismo. Así, en el poema Comunión Plenaria, Girondo confiesa:

\author{
Los nervios se me \\ adhieren al barro, a las \\ paredes, abrazan los \\ ramajes, penetran en la \\ tierra, se esparcen por el \\ aire hasta alcanzar el cielo. \\ El mármol, los caballos
}

Aun cuando solo existe una referencia puntual a la laguna del Tordillo escrita por Francisco Madariaga en alusión a un viaje onírico en tren junto a Oliverio ${ }^{4}$, es cierto que en ninguno de los versos de la obra girondiana aparece citado de manera expresa el paisaje del campo de su infancia y del que tuvo que hacerse cargo tras la muerte de su padre lo que lo llevó visitar con regularidad Dolores para cobrar los arrendamientos rurales hasta que pudo vender la totalidad de las parcelas que había heredado en 1961, es posible arribar a la hipótesis de que las descripciones del paisaje pampeano que el poeta realiza son el resultado de un conocimiento profundo del terruño, de la vivencia interna que provoca la metáfora sentida que desborda la simple observación de una postal o una fotografía y que surge a partir de las imágenes interiores, del amor por la tierra de los ancestros, del deseo y de la comunión íntima con el espacio vivido:

A unos les gusta el alpinismo. A otros les entretiene el dominó. A mí me encanta la transmigración. Mientras aquéllos se pasan la vida colgados de una soga o pegando puñetazos sobre una mesa, yo me lo paso transmigrando de un cuerpo a otro, yo no me canso nunca de transmigrar.

Desde el amanecer, me instalo en algún eucalipto a respirar la brisa de la mañana. Duermo una siesta mineral dentro de la primera piedra que hallo en mi camino y antes de anochecer ya estoy pensando la noche y las chimeneas con un espíritu de gato.

Hablamos de consustanciación porque es elocuente la manera en que la voz del poeta se identifica con el paisaje tan íntimamente que llega a disolverse en él, se le mete en su cuerpo amalgamándose en una comunión de experiencias primarias que diluyen la noción de cuerpo para integrarlo a la totalidad del devenir de los acontecimientos interrelacionados, es decir, a la trama de todo lo vivo. Una forma de ver la realidad donde la noción de yo corpóreo es cuestionada. Qué quiere decir "yo" para el poeta?

Gilles Deleuze sostiene que perseveramos en uno mismo en la medida en que el conjunto de relaciones que nos constituyen es tal que las más complejas no cesan de de pasar en las menos complejas y las menos complejas no cesan de constituir las más complejas. Existe, por lo tanto, una circulación de las relaciones que no dejan de deshacerse y rehacerse. Por eso, "hay que imaginarse el hueso en duración y no en espacialidad. En espacialidad no es una, es esqueleto, es muerto. Pero en perseverancia, en duración, la relación de movimiento y de reposo entre partículas que el hueso representa no deja de deshacerse (...)". (Deleuze, G.: 2015)

En síntesis, Deleuze plantea que el organismo es mucho más que un fenómeno de duración que de espacialidad y, de esta manera, no sólo coincide con la transmigración girondiana sino con Illya Prigogine cuando habla acerca de la flecha del tiempo común que da cuenta de la unidad del universo. "Tu futuro es mi futuro, el futuro del sol y de cualquier estrella" por lo que cualquier acción de una partícula mínima en la

\footnotetext{
${ }^{4}$ Brillan todos los pájaros y estamos viajando al/Paraguay/ Lejos van quedando las costas del Plata y del/ Atlántico,/ Las estaciones /de - "andenes con aliento a zorrino"/De la provincia de Buenos Aires,/Y la laguna del Tordillo. Francisco Madariaga "Viaje al Paraguay con Oliverio" (Fragmento). Publicado en la revista Macedonio No. 3. Invierno 1969
} 
trama de la totalidad interviene de manera aislada sino que perturba el equilibrio dinámico e inestable de aquélla. La voz del poeta lo intuye: No soy yo quien escucha ese trote llovido que atraviesa mis venas.

No soy yo quien se pasa la lengua entre los labios al sentir que la boca se me llena de arena. No soy yo quien espera, enredado en mis nervios, que las horas me acerquen el alivio del sueño, ni el que está con mis manos, de yeso enloquecido, mirando, entre mis huexos, las áridas paredes.

No soy yo quien escribe estas palabras huérfanas.

La intuición de saberse parte de un sistema de relaciones, de ser en tanto se es parte de la trama en movimiento antes que un ser concreto situado en la espacialidad es una presencia constante en la obra de Oliverio Girondo.

Idéntico planteo hace Fritjof Capra cuando se refiere a los problemas ambientales globales que arrecian a la biosfera y a la vida humana y que no pueden ser abordados de manera aisalada sino que se debe hacerlo desde una perspectiva sistémica porque todos ellos convergen en una sola única crisis: una crisis de percepción. Así pues, mientras persistamos en una percepción inadecuada de la realidad que soslaye el concepto de sostenibildad para nosotros y las generaciones futuras, continuaremos siendo impotentes para tratar los problemas de un mundo superpoblado y globalmente interconectado, profundamente desigual $\mathrm{e}$ injusto.

Hemos visto que el abordaje sistémico del paisaje es una de las perspectivas de análisis útil para desentrañar la trama de relaciones que lo constituyen en los ejes sintagmático o de simultaneidad y paradigmático o de historicidad. Ahora bien, si el paisaje es el resultado de acciones naturales y antrópicas y culturales: Qué nos está diciendo el paisaje de los montes desde los millones de años que anteceden a la vida de los seres humanos en la Tierra?

Además de una expresión cultural, el paisaje también es la manifestación externa de los tiempos geológicos, la epidermis de la tierra que se hace visible en la superficie de la tierra porque todo paisaje - como una realidad en sí misma- tiene su propio lenguaje, perfecto como un número áureo, que se expresa a partir de su génesis y del proceso de transformaciones continuas que se producen en la secuencialidad de los tiempos naturales.

Cada uno de los materiales que lo conforman, si bien pueden ser analizados por separado, ello es sólo a los fines heurísticos, porque cobran sentido en la interrelación concatenada a través de la historia de los tiempos. La expresión cultural del paisaje es el resultado de dos instancias: las limitaciones y potencialidades que provee la naturaleza en ese sitio y lo que las personas hacen con ellos para transformarlos y hacerlos habitables.

¿Cómo nació el paisaje que hoy percibimos en los Montes del Tordillo? Debemos distinguir la gestación del paisaje de la génesis de los procesos de transformación que ocurrieron en él. La gestación del paisaje equivale a la descripción geológica mientras que la génesis es la narración aprehensible a través de los sentidos, ya sean: formas, colores, aromas o texturas. Los enunciados que constituyen la narración aprehensible están hechos de los materiales naturales que lo compone y de lo que es producto de sí mismo en la dinámica estacional es decir, la paleta de colores que tiñen la vegetación del lugar y que afloran con cada secuencia de las estaciones. En otras palabras, el paisaje puede ser percibido desde adentro hacia fuera.

Los montes del Tordillo son una regresión marina. Su origen geomorfológico corresponde a una fosa tectónica, o sea, a los movimientos de la tierra que mueven las placas tectónicas y que generaron fosas como huecos rellenadas por sedimentos continentales y marinos sobre los que luego actuó el viento creando cuencas cerradas donde, por deflación o efecto del viento, se formaron cavidades que posteriormente se transformarían en depósitos lacustres permanentes o transitorios .

En el período cuaternario se produjeron los principales aportes que determinaron la conformación de la epidermis de la región pampeana. O sea, el extenso manto loésico fue cubierto de partículas o loes que provienen de la cordillera y que, tras haber sufrido la erosión de origen eólica, se depositaron en la mayor parte del subsuelo de la pampa deprimida, en un espesor de seis metros. (Mapa 1 y 2)

Por su parte, las lagunas que aportaron al paisaje un aspecto de criba palustre -de las cuales la laguna del Tordillo es la más significativa por su tamaño- son testimonio de la ingresión querendiana (Foto Laguna del Tordillo) 
La conformación del loes o material fino proveniente de la cordillera voló para depositarse en las concavidades o la fosa tectónica en un lento y continuo proceso fue configurando lo que es la pampa deprimida, lugar donde se sitúan el paisaje de los montes del Tordillo. Por ende, fue el viento el que con su acción fue moldeando la superficie de la tierra dándole forma de medialunas semilunares salpicadas de relictos de talas y coronillos y, que desde la percepción a la que alude Capra en una escala superior, podríamos conjeturar que equivalen a las manchas del tigre que vislumbró William Miller en sus expediciones al sur del Salado u Oliverio Girondo en su obra poética.(Mapa 4)

Pero como hemos puntualizado más arriba, el paisaje no es sólo procesos naturales sino que es cultura, porque es allí donde tienen lugar las acciones humanas donde el homo faber, al que alude Hanna Arendt, funda un mundo artificial a través de su trabajo por encima de los procesos de la naturaleza y, en esa acción humana, dejas sus huellas en la tierra, las territorializa. Cómo es posible desentrañarlas?

Paul Claval, desde lo que él denominó etnogeografía, se ocupa de la manera en que las diferentes sociedades ordenan y reordenan el espacio. Afirma que cuando un grupo social se instala en un espacio y establece un paisaje, tiene que cumplir las siguientes condiciones: primero, debe reconocerse en el paisaje; segundo, orientarse a partir de él; tercero, marcar su territorio; cuarto, nombrarlo y, quinto, institucionalizarlo. Para el geógrafo francés, reconocerse en el paisaje, consiste en reconocer un sitio o lugar lo que implica descubrir las raíces que vinculan a las personas a él y tal reconocimiento es el resultado de una relación sensorial con el espacio y que va más allá del vínculo familiar. El reconocimiento se saberse parte de la trama de la vida.

Los pasos que enumera Claval pueden sintetizarse en la toponimia de los montes, huellas claras de la apropiación antrópica y, al mismo tiempo, de la construcción social del territorio, del paso de la noción de espacio a la de lugar. De esta manera: "la estancia Girondo", "la manga de Girondo", o "el coronillo de Girondo", devienen significantes que vehiculizan significados y que nos orientan hacia la construcción del horizonte de sentidos que configuran lo que representan los montes del Tordillo para los que lo habitan, lo habitaron y para aquéllos que lo transitan, lo transitaron y que, en su experiencia de movilidad, también fueron dejando sus huellas.

Sin pretensiones de contradecir lo postulado por Rizzo Vast acerca de que el poema largo de Girondo, Campo Nuestro, es una referencia in abstracto a la turbulencia política de la segunda posguerra, un manifiesto político intangible y pacifista que responde con la horizontalidad de la planicie del campo a la turbulencia de aquella época, nuestra hipótesis de partida es otra: postulamos que lo que afirma Rizzo Vast es desterritorializado porque la respuesta panteísta y de elogio de lo rural en Oliverio Girondo no fue un grito inmaterial sino que devino, tuvo lugar, y ese lugar es el paisaje de los Montes del Tordillo.

Si leemos el poema largo a la luz de la territorialidad, la topofilia y la construcción de lugar, el horizonte de significación se amplía y toma nuevas dimensiones. Así pues, el Campo Nuestro de Oliverio Girondo a mediados de la década de 1940: Este campo que fue mar de sal y espuma. Hoy oleaje de ovejas, voz de avena.

Más que tierra eres cielo,

campo nuestro.

Puro cielo sereno...

Puro cielo.

¿De tu origen marino no conservas más

caracol que el nido del hornero?

No olvides que el azar hinchó sus velas

y a través de otra mar dio en tus riberas.

Ante el sobrio semblante de tus llanos se

arrancó la golilla el castellano.

(...)

Los versos del poema largo interpelan a los lectores y los invitan a desentrañar nuevos sentidos, a adentrarse en en el seno de la reproducción social para vislumbrar algunos fragmentos del tejido de la semiosis que la fragmentación transforma en productos. En términos de Eliseo Verón: "La posibilidad de todo análisis de sentido descansa sobre la hipótesis según la cual puede ser (fragmentariamente) reconstruido a partir de una manipulación de los segundos"(Verón, E.: 1993). Entonces, en la teoría de los discursos sociales, es posible 
indagar en los modos de funcionamiento de la semiosis social o en la dimensión significante de los fenómenos sociales a partir del análisis de los productos con objeto de arribar a los procesos.

Una parte de la trama nos invita a aproximarnos a la totalidad a través de sus vínculos.

\section{Conclusión}

Para qué sirve realizar este ejercicio inútil, sobre todo en una época como la nuestra donde la utopía se agota en el consumo individual. Qué utilidad práctica puede tener detenernos a observar nuestros paisajes con nuevos ojos.

Al verte cada vez más cultivado olvidan que tenías piel de puma y fuiste, hasta hace poco, campo bravo.

Puede que, en principio, ninguna. No obstante, la invitación a desentrañar nuevos sentidos además de ser un ejercicio saludable de aproximación a la libertad, invita a hallar respuestas nuevas en un tiempo donde el mayor éxito de la narrativa donde estamos inscriptos es que la realidad es ésta y no hay alternativas y que si la hay, no nos alcanzaría el tiempo vital para hallarlas y resolver los problemas globales que amenazan al planeta.

Espera, campo, espera.

No me llames.

¿Por qué esa voz tan negra, campo

madre?

- ¿Es tu silencio mar quien me reclama?"

-"Ven a dormir a orillas de mi calma."

$\mathrm{Y}$, al mismo tiempo, este ejercicio reflexivo es una invitación a darse cuenta de que todos los paisajes son cultura y que la cultura es un proceso social de producción y reproducción de sentidos por lo que, cada uno de nuestros lugares entrañan relatos, historias significativas que están allí esperando a ser desentrañadas. Quizá sea no sea la salida pero es el inicio de un nuevo camino que nos abren infinitas posibilidades.

\section{Bibliografía}

ANDERSON, B. (1993). Comunidades imaginadas. Reflexiones sobre el origen y la difusión del nacionalismo, FCE, México.

ARENDT, H. (2003): La condición humana. Paidós 1958

ATHOR, J. (Ed.) (2009): Parque costero del Sur. Naturaleza, conservación y patrimonio cultural. Fundación Félix de Azara, Buenos Aires.

BATESON, G. (2002). Espíritu y naturaleza. Amorrortu, 2da. Reimpresión, Buenos Aires.

CAPRA, F.(1996): La trama de la vida. Una nueva perspectiva de los sistemas vivos. Anagrama, Barcelona.

CLAVAL, P. (2002): "El enfoque cultural y las concepciones geográficas del espacio". Boletín de la Asociación de Geógrafos Españoles, №34, pp. 21-39.

CAMPOMAR, M. (2016). Ortega y Gasset. Luces y sombras del exilio argentino. Biblioteca Nueva, Fundación Ortega y Gasset Argentina, Madrid.

DELLEUZE, G. (2008): En medio de Spinoza. Cactus, Buenos Aires.

GIDDENS, A., (et. al. ) (comp.) (1996). Las consecuencias perversas de la modernidad:

modernidad, contingencia y riesgo. Anthropos, Barcelona.

GIRONDO, O. (2000). Noche tótem. Selección y prólogo de Daniel Freidemberg. Colihue, Buenos

Aires.

GIRONDO, O. (1996): Obra. Losada. 1968.

López Levi, Liliana y Ramírez Velázquez, Blanca R. (Sin fecha): "Pensar el espacio: Región, paisaje, territorio y lugar en las ciencias sociales'. : www.posgrado.unam.mx/geografia/admision/espacio.pdf (Consulta:01/03/2018)

Mascioli, A. (2002): 'Caminos de acceso al usufructo y propiedad legal de la tierra en la frontera bonaerense. Dolores, 1798-1860". Revista Quinto Sol, No 6

Madariaga, Francisco (1969): "Viaje al Paraguay con Oliverio" (Fragmento). Revista Macedonio No.

3. Invierno 1969, 
MEO LAOS, V. , CASALI URRUTIA, M. (2012): "Oliverio Girondo en el paisaje pampeano. Una sensible mirada sobre el lenguaje del poeta, su relación con el paisaje y el patrimonio". Revista Habitat. Conservación, reciclaje \& restauración. No 71. agosto 2012.

MEO LAOS,V., URRUTIBEHETY, G. y PIRALI, J. (2011). Tras las huellas de Girondo. De muertos y revivos yoes. Imago Mundi, Buenos Aires.

NOGUÉ, J. (2010): "El retorno al paisaje". Universitat de Girona. Departament de Geografia.Paisaje cultural. Recuperado de: itpack31.itarget.com.br/uploads/anp/.../paisaje2010-Joan-Nogue.pdf (Consulta:01/03/2018)

PIRALI, J. (2010): Album histórico de Dolores. Origen, evolución, instituciones, personalidades, transporte, periodismo, educación. Emprendimiento Editorial C. A. S. Dos de Abril, Dolores, Buenos Aires.

PRIGOGINE, I. (1996): El fin de la certidumbre. Andrés Bello, Santiago.

RECLUS, E.(2004): El arroyo. The Proyect Gutemberg E book.

https://grupodeestudiosgomezrojas.files.wordpress.com/2009/12/reclus-eliseo-el-arroyo.pdf

(Consulta:01/03/2018)

RETAMOSO, R. (2005). Oliverio Girondo. El devenir de su poesía. UNR Editora, Rosario.

RIZZO VAST, P. (2001): "Paisaje e ideología en Campo Nuestro de Oliverio Girondo. Revista Iberoamericana. Vol. LXVII, Núms. 194-195, Enero-Junio 2001, 105-120.

TUAN, YI FU (2007). Topofilia. Un estudio de las percepciones, actitudes y valores sobre el entorno. Melusina, Barcelona.

VARGAS ULATE, G.(2012): "Espacio y territorio en el análisis geográfico". Reflexiones, vol. 91, núm. 1, 2012, pp. 313-326. Universidad de Costa Rica. San José, Costa Rica.

VERÓN, E.(1993): La semiosis social. Gedisa, Barcelona.

ZUSMAN, P., LOIS, C. y CASTRO, H. (comp.) (2007). Viajes y geografías. Exploraciones, turismo y migraciones en la construcción de lugares. Prometeo, Buenos Aires.

\section{DOSSIER DE IMÁGENES}

La técnica empleada para el procesamiento e integración de la información fue a partir de la utilización de un Sistema de Información Geográfica. La cartografía básica utilizada para encarar la investigación es la generada por el INTA Instituto de Clima y Agua (Mapa 1) y por el Centro de Investigaciones y Ambientales Bonaerenses (CITAB - Bco. Provincia) (Mapa 2).

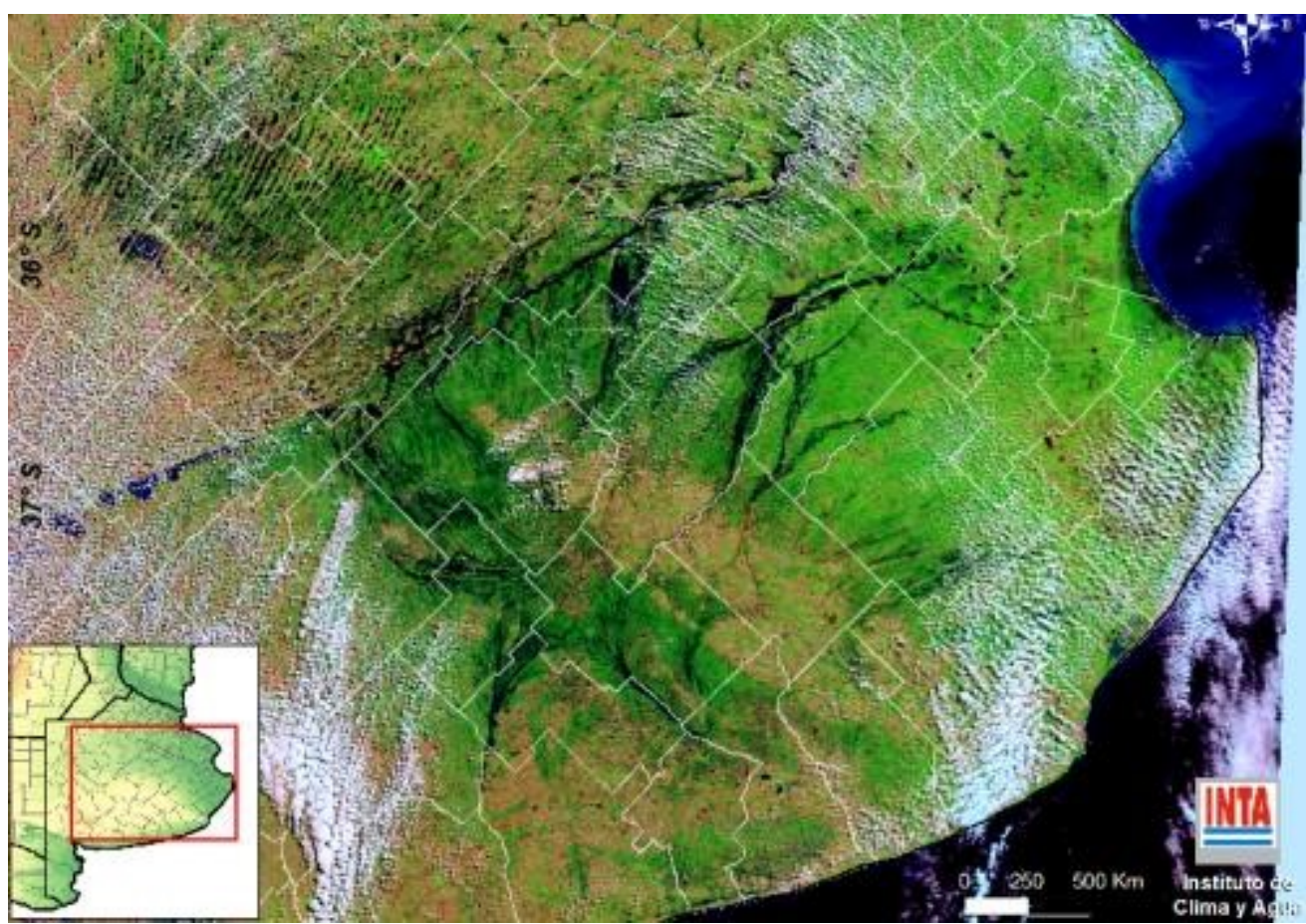

(Mapa 1) 


\section{REGIONES GEOGRAFICAS DE LA PROVINCIA DE BUENOS AIRES}

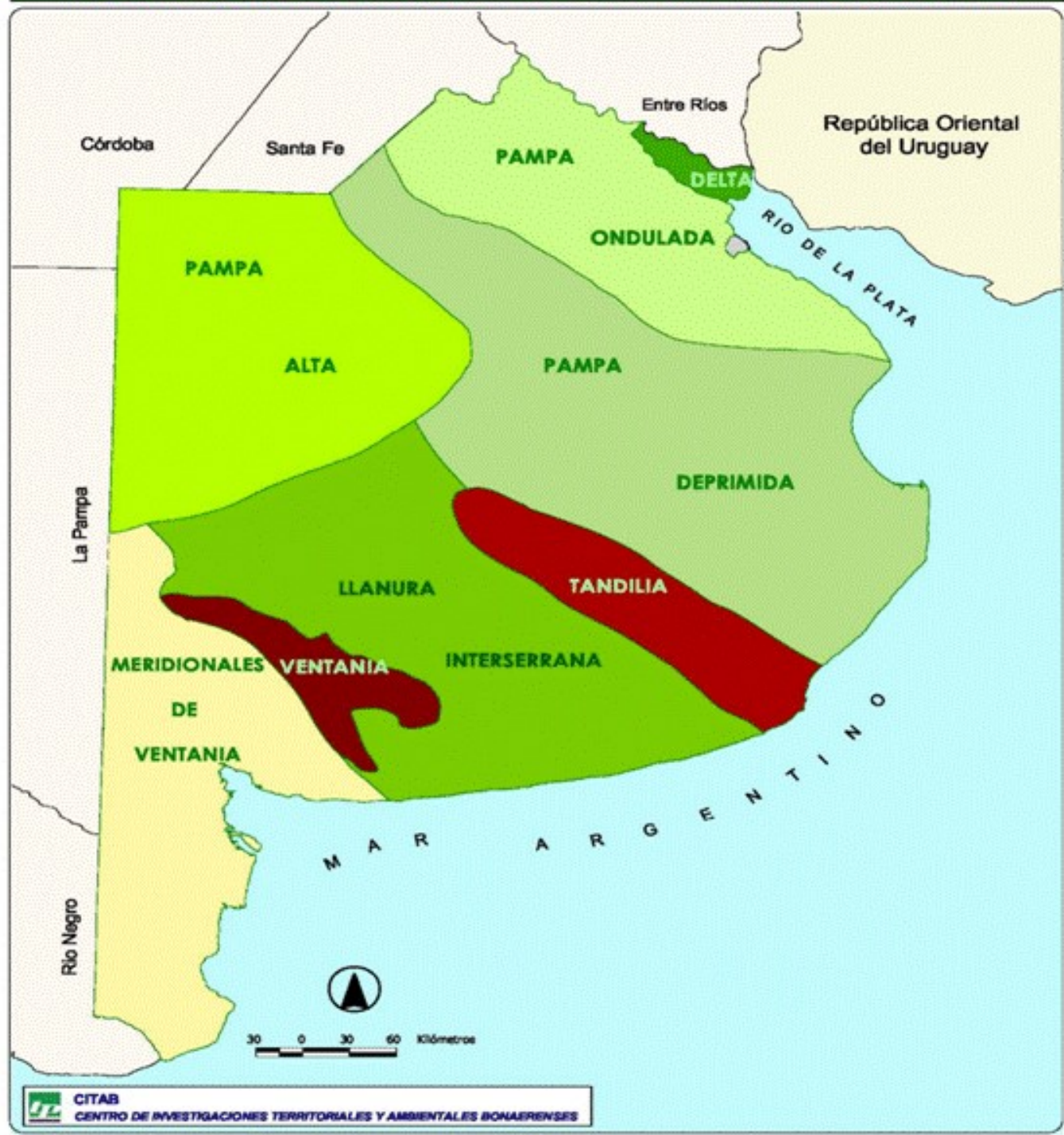

(Mapa 2) 


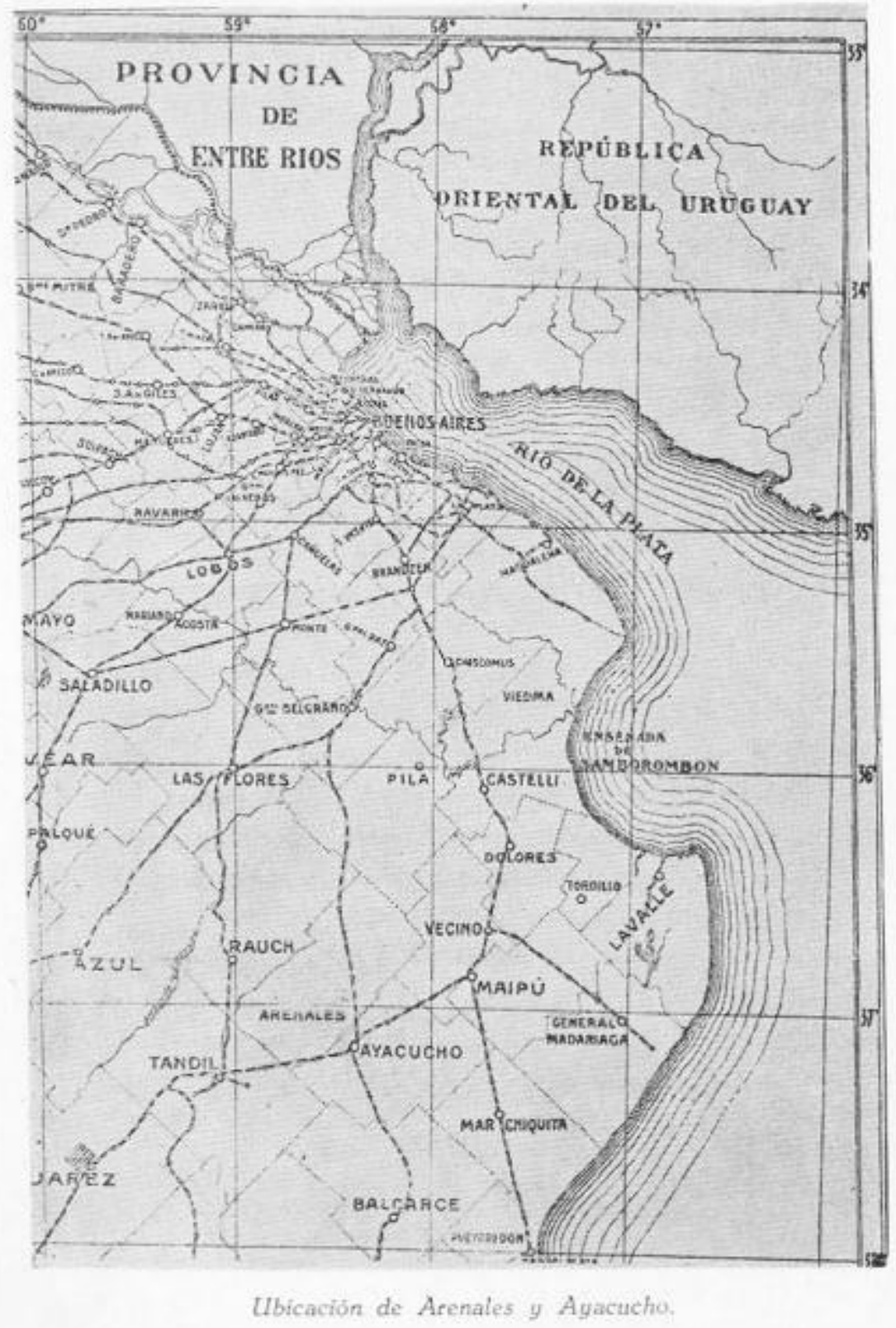

(Mapa 3: Década de 1860. Fuente: AZEVES, Héctor. 1968. Ayacucho. Surgimiento y desarrollo de una ciudad pampeana . Buenos Aires) 


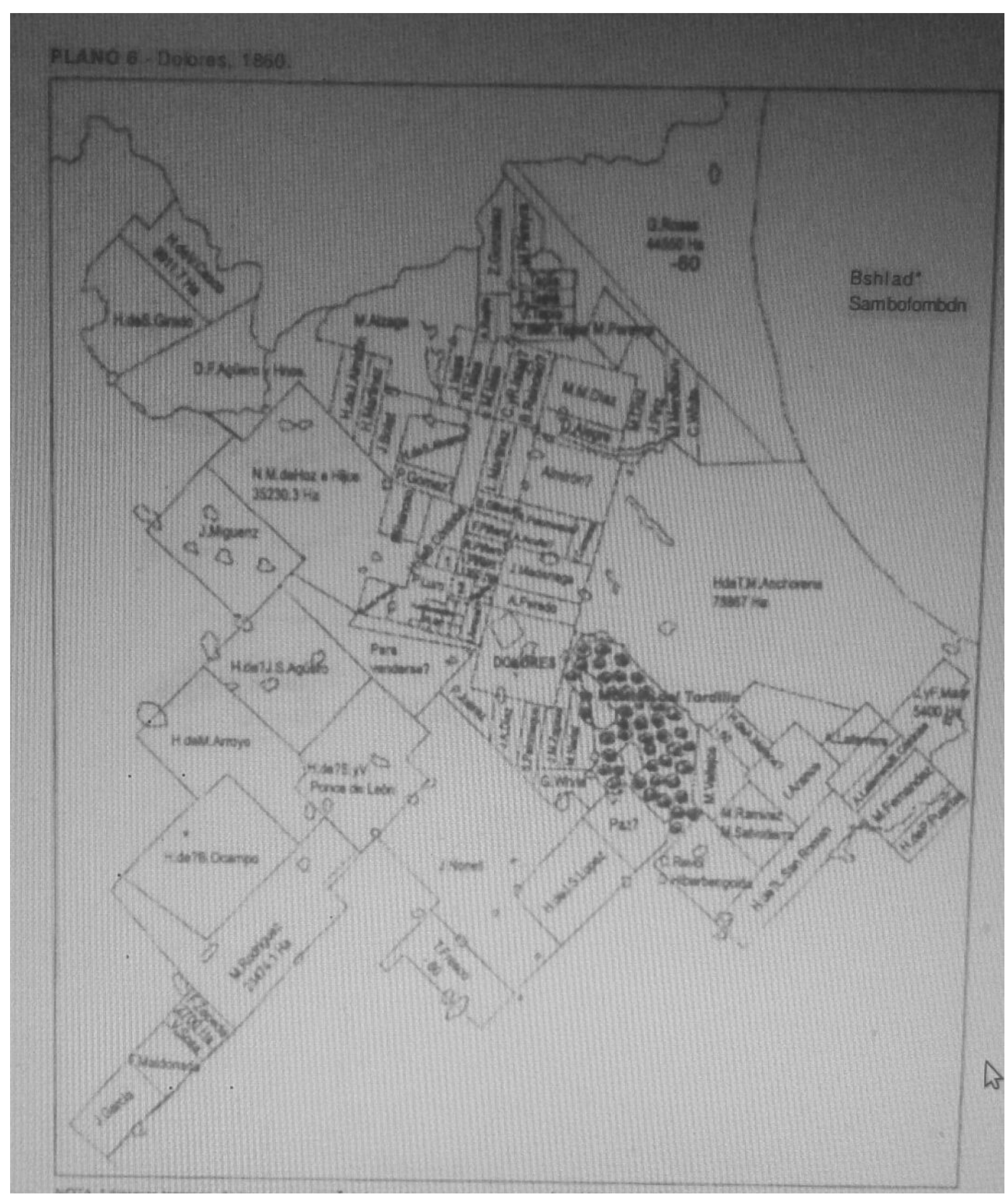

(Mapa 4.FUENTE: Elaborado por Facultad de Ciencias Humanas - Universidad Nacional de la Pampa, con base a duplicados de miniaturas de los partidos de Dolores, Castelli, Tordillo. Pila, Gral. Lavalle y Gral. Guido; Mensuras Antiguas al sur del Salado; Registro gráfico de la provincia de Buenos Aires (1864) (AHG y G); Legajos varios de la sección Escribanía Mayor de Gobierno (AHPBA) 


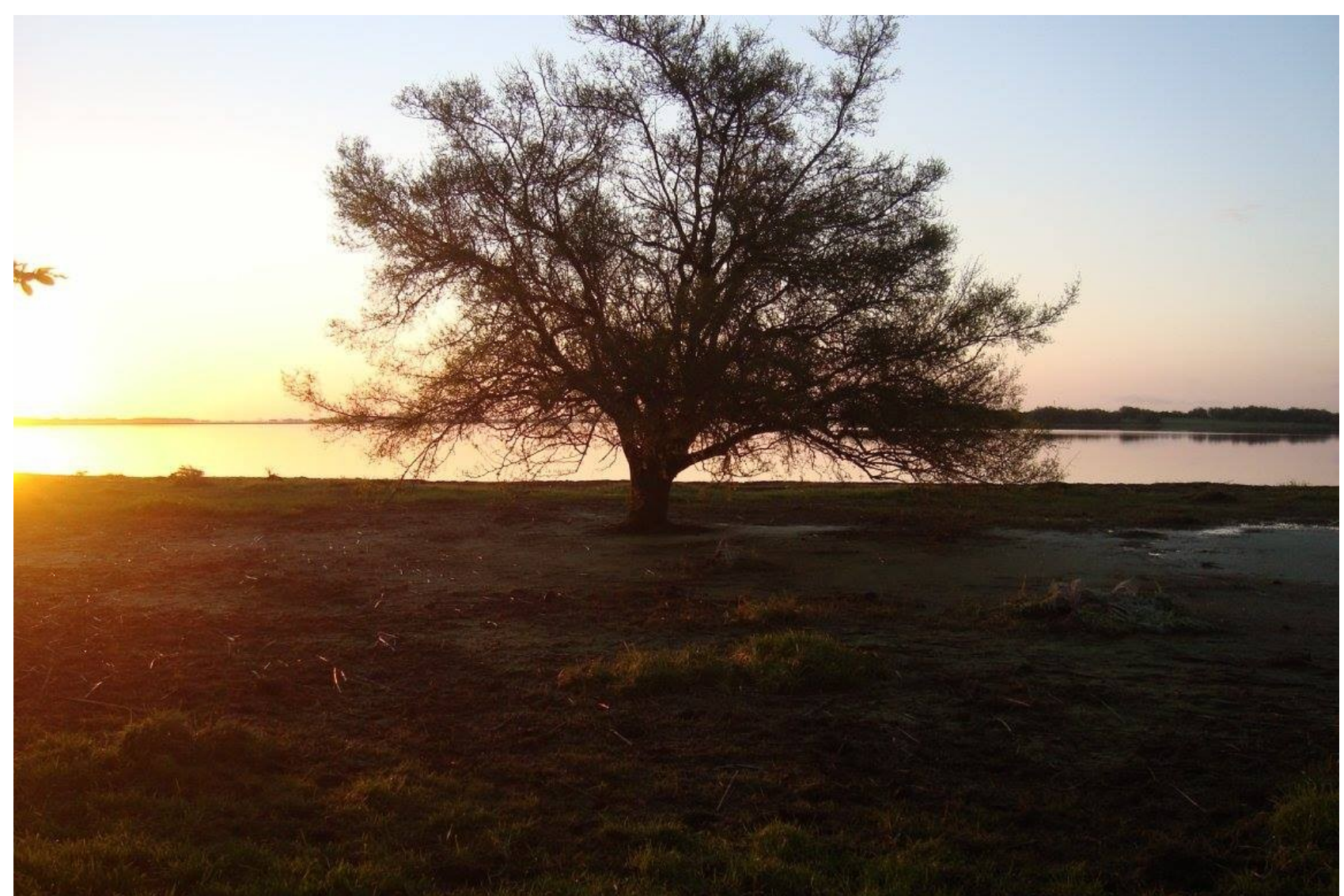

Foto: Laguna del Tordillo 